\title{
O FEMICÍDIO NA INTIMIDADE SOB O OLHAR DOS MEDIA: REFLEXÕES TEÓRICO-EMPÍRICAS
}

\author{
Ariana Pinto Correia \\ Faculdade de Psicologia e de Ciências da Educação da Universidade do Porto (FPCEUP). Email: \\ ariana.pinto.correia@gmail.com. \\ Sofia Neves \\ Instituto Universitário da Maia (ISMAI). Centro Interdisciplinar de Estudos de Género (ISCSP/ULisboa). \\ Email:asneves@ismai.pt \\ Sílvia Gomes \\ Centro Interdisciplinar em Ciências Sociais da Universidade do Minho (CICS.Nova/UMinho) \\ Instituto Universitário da Maia (ISMAI).E-mail: silvia.gomes@ics.uminho.pt ou silvia.gomes@ismai.pt \\ Conceição Nogueira \\ Centro de Psicologia da Universidade do Porto (CPUP). Email: cnogueira@fpce.up.pt
}

Resumo: O presente texto versa sobre o olhar dos media em torno do femicídio na intimidade, uma das mais severas manifestações de violência de género. Considerando a investigação que tem vindo a ser produzida sobre o impacto das narrativas mediáticas da imprensa escrita e da televisão sobre o femicídio na intimidade, ao nível das representações sociais e das práticas criminais, junto de diferentes grupos sociais, são aqui problematizadas as características e as implicações das narrativas mediáticas construídas em torno do fenómeno, bem como as suas condições de noticiabilidade. Defendese a necessidade de investir numa perspetiva de literacia crítica para os media que potencie um entendimento sobre a ideologia de género que está na base e sustenta a violência contra as mulheres, tal como recomendado na Convenção do Conselho da Europa para a Prevenção e o Combate à Violência contra as Mulheres e a Violência Doméstica.

Palavras-chave: Violência de género, femicídio na intimidade, media.
Abstract: This paper aims to reflect on the ways news media portray intimate femicide. Taking intimate femicide as one of the most severe expressions of gender violence and relying on recent research on the impact of media narratives on this phenomenon, the characteristics and implications of these media narratives and its newsworthiness are problematized. Research review is centered specifically on studies about press and television focusing both on social representations of crime and 
intimate femicide, and on the criminal practice in different social groups. It is argued the need of a critical media literacy approach to the matter. Such an approach promotes an understanding of the ideology of gender that underpins and sustains violence against women, which is recommended in the Council of Europe Convention on Preventing and Combating Violence against Women and Domestic Violence.

Keywords: Gender violence, intimate femicide, media.

\section{Introdução}

A violência de género é uma das mais graves violações dos direitos humanos, em particular das mulheres, colocando em causa a sua dignidade e o seu acesso pleno à democracia. Por forma a contrariar manifestações sistémicas de hegemonia masculina, têm sido várias as recomendações de organismos europeus e internacionais, ao longo das últimas décadas, no sentido de se intensificarem os esforços, por parte dos Estados, para eliminar um flagelo que se reconhece existir à escala mundial.

A Convenção do Conselho da Europa para a Prevenção e o Combate à
Violência contra as Mulheres e a Violência Doméstica (Conselho da Europa, 2011), também designada por Convenção de Istambul, é um dos mais recentes instrumentos, criados ao abrigo de um compromisso europeu, a pugnar pela proteção das vítimas e pela responsabilização dos agressores. Perspetivando a violência contra as mulheres como violência de género, a Convenção de Istambul assenta no pressuposto de que esta é

$$
\begin{aligned}
& \text { uma manifestação das relações de } \\
& \text { poder historicamente desiguais } \\
& \text { entre mulheres e homens que } \\
& \text { levou à dominação e } \\
& \text { discriminação das mulheres pelos } \\
& \text { homens, privando assim as } \\
& \text { mulheres do seu pleno progresso } \\
& \text { (Conselho da Europa, 2011:2). }
\end{aligned}
$$

Reforça-se neste documento o entendimento de que a violência contra as mulheres deriva de assimetrias estruturais promotoras de desigualdades de género (Azambuja et al., 2013; Neves, 2008; Neves e Nogueira, 2010), que se repercutem em todas as dimensões da vida social, muito em particular na esfera das relações de intimidade.

Um estudo recente, realizado com uma amostra de 42 mil mulheres 
oriundas dos 28 Estados Membros da União Europeia, concluiu que uma em cada 10 mulheres, a partir dos 15 anos, já experienciou alguma forma de violência sexual e que uma em cada 20 diz já ter sido violada (FRA, 2014). Contudo, apenas $14 \%$ das mulheres inquiridas referiram ter reportado os incidentes violentos (passados ou presentes) às autoridades policiais e apenas $13 \%$ o fizeram quando os atos foram perpetrados por estranhos (FRA, 2014).

Neste estudo, como em outros (e.g., WHO, 2013), está patente a forma como a violência de género afeta desproporcionalmente as mulheres, numa contínua transgressão dos seus direitos, resultado da posição subordinada a que as mesmas têm sido relegadas (Amâncio, 1994; Dobash, 2004). Sob o argumento das diferenças sexuais naturalizou-se, desde a antiguidade, um discurso biologizante e essencialista que atribui às mulheres uma determinada essência (Amâncio, 1993: 128), por contraste à essência dos homens, a qual as coloca numa situação de subalternidade (Neves e Nogueira, 2003). No seio destas assimetrias de poder, que são transmovidas para as relações de intimidade, valida-se o primado da superioridade masculina. Em consequência, a vulnerabilidade das mulheres aos vários tipos de violência na intimidade assume um caráter marcadamente político (Nogueira e Azambuja, 2007).

Como expoente máximo da violência de género, e especificamente da violência perpetrada contra as mulheres, encontra-se a prática do femicídio. Embora a sua origem seja anterior à década de 1970, o termo femicídio aparece referenciado nessa altura pela feminista Diana Russell com o objetivo de denunciar o assassinato de mulheres motivado pelo ódio dos homens (Russell e Radford, 1992). Reconhecendo que a adoção do vocábulo ecoa o caráter genderizado do crime, que até à data se diluía na neutralidade do termo homicídio, Russell utilizou-o pela primeira vez em 1976, durante o seu depoimento perante o Tribunal Internacional de Crimes contra as Mulheres. Definido como "o homicídio de mulheres perpetrado por homens, porque estas são mulheres" (Russell e Harmes, 2001: 13), a expressão femicídio viria a ser mais tarde redefinida por Jane Caputi e Diana Russell (1992), enfocando-o como o fim extremo de um continuum de terror 
patriarcal que inclui uma variedade de privações e abusos físicos, psicológicos e sexuais a que as mulheres vítimas de violência são submetidas durante as suas vidas. Nesta ótica, o femicídio não designa um evento isolado ou uma ação ou intenção motivada pela passionalidade, antes o culminar de um processo abusivo (Campos, 2015), associado à misoginia (Baldry e Ferraro, 2008).

A utilização da palavra femicídio concorre, pois, para a desmitologização da noção de privacidade do espaço íntimo (Neves, 2007, 2008; Nogueira e Neves, 2003), distanciando-se de uma visão apoiada na tese da conflitualidade interpessoal ou familiar, muitas vezes defendida pelas Ciências Sociais e Humanas, especialmente pela Psicologia (e.g., Dutton e Nicholls, 2005), e reforçada pelos media, para explicar a violência contra as mulheres.

Dentre as formas mais graves de violência de género na intimidade, o femicídio é a mais severa de todas, não apenas pela sua gravidade, mas também pela sua complexidade. Evidências de 66 países mostram que $13.5 \%$ dos homicídios são cometidos no seio de relações de intimidade, sendo as mulheres seis vezes mais vitimadas do que os homens (Stöckl et al., 2013). Em 2012, 47\% das mulheres assassinadas a nível mundial foram-no por familiares ou parceiros, totalizando 43.600 mortes (UNDOC, 2014). Nos crimes perpetrados por mulheres contra homens, casos estatisticamente menos expressivos, a literatura sugere $\mathrm{o}$ recurso à legítima defesa, tendo sido o crime cometido em resposta a ameaça(s) física(s) prévia(s) ou a tentativa(s) de homicídio por parte dos parceiros ou ex-parceiros (Carlyle et al., 2008; Smith, Moracco e Butts, 1998). Tais dados suportam a ideia de que o femicídio é um problema de saúde pública (Angelo et al., 2008; Richards et al., 2014), que tende a manifestar-se como um processo continuado no tempo, ou seja, de forma crónica, em resultado de um histórico de abuso.

Para além dos estudos que procuram a sistematização de dados sobre a prevalência do femicídio na intimidade, outros têm-se debruçado sobre o impacto dos discursos mediáticos na construção social do crime e na manutenção/proliferação das suas práticas. O propósito cimeiro destes últimos é analisar o papel dos media como agentes de conhecimento e de construção de realidades sociais e os 
possíveis efeitos das narrativas que propagam, junto de diversos atores/as sociais, nas representações sobre 0 crime e nas próprias ações criminais. Entende-se, pois, que - além do conhecimento em torno do perfil das vítimas, dos agressores, dos processos e das dinâmicas do femicídio na intimidade - é necessário escrutinar as narrativas que são produzidas e legitimadas pelos media aquando da veiculação de notícias sobre o fenómeno, reconhecida que está a sua potencial influência ao nível das atitudes e dos comportamentos, nomeadamente das vítimas e dos agressores. Esta necessidade é inclusivamente assinalada no âmbito da Convenção de Istambul que, no seu artigo $17 .^{\circ}$, refere que o sector privado, o sector das tecnologias da informação e da comunicação, dentro do devido respeito pela liberdade de expressão e pela sua independência, devem participar na elaboração e implementação de políticas, assim como no estabelecimento de diretrizes $\mathrm{e}$ normas de autorregulação para prevenir a violência contra as mulheres e para reforçar o respeito pela sua dignidade (Conselho da Europa, 2011: 12).
Este artigo tem como principal objetivo discutir a questão do crime e do género nas notícias, problematizando as características das narrativas mediáticas sobre $\mathrm{o}$ femicídio na intimidade, bem como as suas condições de noticiabilidade. Neste sentido, apresentam-se, numa primeira fase, alguns dos estudos sobre os media que se têm vindo a debruçar sobre a relação entre o género e o crime e, em particular, sobre a relação entre o género e o femicídio na intimidade. Discutem-se, em seguida, os impactos das narrativas mediáticas sobre este crime na construção e/ou reprodução de narrativas em torno das vítimas, dos agressores e das dinâmicas criminais, argumentando-se, numa fase final, a indispensabilidade da adoção de uma perspetiva de literacia crítica para os media.

\section{O crime e o género nas notícias: as narrativas mediáticas sobre o femicídio na intimidade}

Os media (informativos) não são veículos, canais ou tecnologias neutras, operando antes como fontes de influência nos espaços económico, político, social e cultural (Pinto et al., 
2011). A sua presença nas sociedades atuais é determinante na produção e difusão de certas visões, representações, atitudes e comportamentos, nomeadamente sobre o crime (Gomes, 2015; Penedo, 2003), pelo que constituem um "poderoso aparelho ideológico" (Mendes, 2004: 153). Qualquer narrativa mediática é construída, baseia-se e reflete as crenças e os valores vigentes em determinada sociedade (Meyers, 1997).

Os meios de comunicação social possuem um papel central na sociedade contemporânea, já que a partir da modelação da opinião pública se podem estimular ou repulsar medidas de prevenção ou intervenção na área da violência de género (Morelli e Rey, 2011). As perspetivas psicológicas e sociológicas sobre os efeitos dos media nos indivíduos ou nas sociedades são apenas algumas das que procuram estabelecer relações entre as narrativas mediáticas e o crime, salientando os mecanismos de inter-influência que nelas operam. Devido ao poder que os meios de comunicação social têm em condicionar a opinião pública, bem como o sistema judicial e os poderes políticos, a investigação com enfoque nos media tem crescido exponencialmente nas últimas décadas, especialmente a partir de 1970, época em que os estudos feministas dos media trouxeram para a agenda académica as questões do poder, dos direitos, dos valores e da representação das mulheres (Gallagher, 2014).

Para além de participarem na formação de conhecimento e na construção social da realidade (Berger e Luckmann, 2004), os meios de comunicação social são igualmente instrumentos simbólicos, que refletem e (re)produzem relações de poder que dependem, na forma e no conteúdo, do referencial material ou simbólico acumulado pelos agentes (ou instituições) envolvidos nessa relação (Bourdieu, 1994 apud Pina, 2009: 5758). Como agentes (re)produtores de relações de poder e, por conseguinte, de relações sociais de género, os meios de comunicação social espelham ideologias dominantes. Taylor (2009) e Carlyle et al. (2014) defendem mesmo que, ao fazê-lo, os meios de comunicação social, e no que diz respeito especificamente aos temas relacionados com o género, em particular com a violência de género, contribuem para a desinformação e a naturalização de estereótipos, mitos e 
preconceitos (Carlyle et al., 2014; Taylor, 2009).

Os meios de comunicação social, sendo veículos de influência social (Castro et al., 2012), podem ora reforçar o silenciamento das mulheres e a visão parcial da condição feminina, ora promover o seu potencial emancipatório (Cerqueira, 2012). Constata-se, contudo, que as narrativas mediáticas tendem a promover uma imagem cristalizada da ordem de género (Connell, 2002), não fomentando, em consequência, narrativas que favoreçam o potencial emancipatório das mulheres.

\section{Quando o crime e o género são notícia}

As notícias sobre o crime são das mais populares e das mais constantes no total das notícias veiculadas pelos meios de comunicação social (Machado e Santos, 2008; Penedo, 2003). Além desta tendência para a cobertura significativa do crime, outro elemento que caracteriza este tipo de notícias é a forma como são relatadas as histórias dos alegados criminosos e respetivas vítimas e os sentimentos que estas histórias, consequentemente, provocam no público, alimentando estereótipos vários de pessoas e/ou grupos sociais e mitos sobre o crime (Gomes, 2015; McCombs, 2002). Neste sentido, dos muitos temas que podem ser encontrados nos meios de comunicação social, o da justiça e o do crime são referidos como sendo os mais reveladores daquilo que é a ideologia de determinada sociedade, envolvendo noções do bem e do mal, moralidade, realização e estrutura social (Surette, 1998: 37-38).

Sobre a popularidade das notícias sobre o crime nos media, Surette (1998), fazendo uma síntese dos pontos de vista de diversos autores/as, aponta três possíveis explicações gerais para a sua cobertura: a) as notícias sobre o crime são descritas como servindo uma função social positiva, ao definirem o limite do comportamento social aceitável, dissuadindo os infratores, acautelando as potenciais vítimas e fornecendo vigilância sobre o crime; b) o crime é também uma questão social importante, pois coloca em causa a ordem social e, portanto, as notícias do crime são difundidas por forma a retratar o mundo em que vivemos; e, por fim, correspondendo ao pragmatismo e sustentabilidade financeiros dos órgãos de comunicação 
social c) as notícias sobre o crime aumentam a circulação e têm valor de entretenimento para as empresas que detêm esses órgãos.

O problema das notícias sobre o crime não está no facto de serem notícia, mas na frequência com que estas são difundidas, empolando a importância do crime na vida das pessoas, pelo que noticiam e pela forma como o noticiam (Gomes, 2013, 2015). Exemplificando, as notícias mostram um mapa dos eventos criminais que difere daquele que é facultado pelas estatísticas oficiais do crime (Katz, 1987: 57; Sacco, 1995: 143). Na realidade, os media tendem também a dar mais relevo não só aos crimes violentos (que, por serem mais incomuns, têm maior valor-notícia), mas a crimes cometidos por estranhos, mais do que por conhecidos ou familiares (os casos de violência doméstica, por exemplo, são menos vezes relatados do que os crimes de rua, como os homicídios e os assaltos) (Pina, 2009: 111). Mais, os relatos de factos criminais esgotam-se normalmente na descrição da sua consumação e consequências imediatas e, raras vezes, esses factos são analisados a partir de perspetivas críticas alargadas ou distanciadas (Carvalho, 2007). Problemas habitualmente associados pelas Ciências Sociais ao crime, como a pobreza, o desemprego, a saúde, a baixa escolaridade, a deterioração das relações comunitárias, a iliteracia e outros, são geralmente omissos no tratamento de casos criminais por parte dos media (Pina, 2009: 110).

A relação entre crime e género, introduzida de forma mais sistemática nas últimas décadas no discurso mediático, tem vindo a ser explorada pelos media a partir de diferentes prismas. Quando o foco da notícia é o crime praticado pelas mulheres, este tende a conter elementos sensacionalistas, voltados para a sua diabolização e sexualização (Jewkes, 2011). Como sugerem Duarte e Cunha (2014), o comportamento agressivo protagonizado pelas mulheres é inconsistente com os estereótipos sociais femininos. Não correspondendo ao papel social que lhes está destinado, as mulheres são caracterizadas geralmente como sujeitos com perturbação ou desvio que contariam a ordem natural de género. $\mathrm{O}$ mesmo argumento parece servir de referência para os casos em que as mulheres são vítimas de crime no contexto da 
intimidade. Assunções sobre o facto de serem más mães ou más companheiras são frequentes, não apenas na descrição dos atos criminais em que as mulheres figuram como autoras, mas também nos que figuram como vítimas.

Nancy Berns (2004) identificou três perspetivas patentes na abordagem que os media fazem dos casos de violência contra as mulheres na intimidade: a) a perspetiva do empoderamento das vítimas, b) a perspetiva da culpabilização das vítimas (anti-feminista) e c) a perspetiva da justiça social. De acordo com a autora, a perspetiva dominante é aquela que se orienta pela responsabilização das vítimas (a segunda), salientando aquilo que elas poderiam ter feito para evitar a violência. Portanto, o discurso mediático não só individualiza o problema, como também o constrói em torno da culpabilidade das vítimas, desviando a atenção da opinião pública do enquadramento cultural, institucional e estrutural da violência de género. Tal abordagem encontra sustentação nos pressupostos das teorias clássicas da Vitimologia, as quais concebem as vítimas como responsáveis (parcial ou integralmente) pelos crimes de que são alvo (e.g., von Heting, 1948).
Por sua vez, Sutherland (2015) sistematizou três tipos de abordagens que problematizam as questões do tratamento noticioso da violência contra as mulheres (Sutherland, 2015): a) a abordagem da representação, que explora a natureza dos conteúdos e dos discursos sobre a violência contra as mulheres; b) a abordagem da receção da audiência, que estuda o modo como as audiências interpretam as notícias sobre a violência contra as mulheres e como o risco é percebido e gerido por elas e; c) a abordagem da produção das notícias, que procura analisar as práticas de recolha e de divulgação de informação sobre a violência contra as mulheres e os/as seus/suas filhos/as. A título ilustrativo, evidências de vários estudos sugerem que as audiências são condicionadas pelos media na interpretação que fazem das notícias sobre a violência sexual contra as mulheres, sendo esta influência significativa, por exemplo, na legitimação de mitos sobre a violação (e.g., Meyer, 2010).

Assim, e face ao exposto anteriormente, é possível identificar algumas tendências da comunicação mediática quando as notícias versam sobre a violência contra as mulheres 
(Sutherland, 2015): a) não referência ao contexto social no âmbito do qual a vitimação é perpetrada; b) sensacionalização ou desproporcionalização das histórias através do uso de uma linguagem inapropriada; c) perpetuação de mitos e estereótipos; d) culpabilização direta ou indireta das vítimas e desresponsabilização dos agressores e; e) privilégio da informação proveniente das fontes oficiais em detrimento de especialistas.

Daqui se conclui que quando as mulheres vítimas são notícia, os processos de vitimação a que foram sujeitas pelos agressores são habitualmente secundarizados e negligenciados, tendência que se adensa quando a comunicação mediática incide sobre o femicídio na intimidade.

\section{Quando o femicídio na intimidade é notícia}

Os aspetos anteriormente explanados sobre o crime nas notícias são também visíveis nos estudos que se debruçam, especificamente, sobre o femicídio na intimidade e que fazem a necessária interseção entre crime e género.
A investigação feminista tem demonstrado que a representação das mulheres nos meios de comunicação social é análoga ao seu status na sociedade （Comas-d'Argemir， 2014; Croteau e Hoynes, 1997 apud Richards et al., 2011; Simões, 2008). Este retrato inclui atitudes e representações que suportam e intensificam papéis de género hierarquizados. Sob o argumento da subalternização e submissão das mulheres, a violência tem sido utilizada como uma ferramenta de controlo e de dominação masculina, na linha de uma tradição patriarcal que se vê legitimada pelos discursos mediáticos (Buiten e Salo, 2007). Lakoff (1982: 45 apud Cerqueira, 2008) indica que "a marginalidade e a falta de poder das mulheres refletem-se não só nos modos como se espera que as mulheres falem, mas também nos modos como se fala das mulheres". Por isso, as narrativas mediáticas sobre as mulheres e, mais em concreto, sobre a violência contra as mulheres, funcionam como uma espécie de barómetro social de valores e crenças de género.

Os estudos têm vindo a demonstrar que, nos casos de femicídio na intimidade, os media tendem a culpabilizar as vítimas e/ou a 
desresponsabilizar os agressores, relegando os casos de vitimação na intimidade para a esfera do privado e reproduzindo os discursos socialmente instituídos (Belknap, 2007). As questões de género são, assim, remetidas para segundo plano ou não são consideradas de todo, sendo $\mathrm{o}$ femicídio tratado como um crime que resulta de motivações passionais, ou seja, da conflitualidade relacional movida pela paixão ou pelo amor doentio. A romantização do femicídio mascara a sua dimensão estrutural (Jankey, 2009), descontextualizando-o de uma matriz analítica politicamente implicada.

Neste sentido, os media insistem em descrever a violência de género como um conjunto de episódios de caráter interpessoal, excluindo das narrativas mediáticas as dinâmicas sociais que estão na sua génese (Bullock e Cubert, 2002; Taylor, 2009). Gillespie et al. (2013) referem que só muito recentemente a violência na intimidade surge nos meios de comunicação social como um problema público, o que faz com que haja uma resistência social em considerá-lo fora do domínio das relações familiares estritas, tradicionalmente tratadas como sendo alheias à intervenção do Estado (Dias, 2005; Neves, 2008).

De acordo com McManus e Dorfman (2003 apud Wozniak e McCosley, 2010), a cobertura noticiosa de casos de femicídio na intimidade é menor do que a de homicídios perpetrados por estranhos. Mais ainda, a cobertura de casos de femicídio na intimidade tende a ter menor visibilidade, profundidade e contextualização, resultando, por inerência, em menor precisão (Richards et al., 2011; Taylor e Sorenson, 2002). Fruto de lógicas comerciais, os media tornam frequentemente as histórias de violência na intimidade, quando as veiculam, mais vendáveis, dramatizando-as e simplificando-as (Wozniak e McCosley, 2010).

A cobertura noticiosa destes casos, como lembra Taylor (2009), caracteriza-se pela exacerbação dos elementos que concorrem para a culpabilização das vítimas, enfatizando atributos que põem em causa a sua credibilidade ou as suas competências. Não raras vezes, a conduta das vítimas é objeto de uma apreciação negativa que serve o intuito de justificar a sua quota parte de responsabilidade ou a sua responsabilidade integral no crime de 
que foram alvo. A promiscuidade sexual, o abuso de substâncias ou o desempenho deficitário dos papéis de género são questões frequentemente aludidas para esgrimir a culpa das mulheres nos processos de vitimação que lhes são dirigidos (Angélico et al, 2014; Pereyra, 2001; Taylor 2008; Taylor, 2009). Também a inexistência de denúncia, a retirada de queixa (nas situações em que tal é permitido por lei) e a parca colaboração com o sistema de justiça são indicadores que servem para atestar a culpabilidade das vítimas (Gillespie, et al., 2013; Richards et al., 2011).

Bullock e Cubert (2002) verificaram que apenas um quarto dos crimes de femicídio na intimidade é, nas notícias, associado diretamente à violência na intimidade e apenas $10 \%$ dos casos são contextualizados no espectro da violência de género. Uma investigação conduzida por Wozniak e McCloskey (2010) concluiu que em $72 \%$ das notícias sobre femicídio na intimidade publicadas pela imprensa não é feita qualquer menção à existência de historial prévio de vitimação, pese o facto de cerca de $75 \%$ das mulheres assassinadas pelos parceiros ou ex-parceiros serem vítimas destes antes de serem mortas (Campbell et al., 2007). Quando a referência à história prévia de violência é feita, esta é geralmente sob a indeterminação do advérbio alegadamente, criando nos/as leitores/as a dúvida sobre tal evidência (Consalvo, 1998). As situações que problematizam as questões da legítima defesa são escassas (Wozniak e McCloskey, 2010), o que acompanha, aliás, uma tendência do sistema judicial.

Para além das táticas diretas de culpabilização das vítimas, elencadas anteriormente, destacam-se as indiretas, tais como a patologização do agressor ou a falácia do sistema. O descontrolo face a uma situação limite (motivada quase sempre por ciúmes e suspeitas de infidelidade), o consumo excessivo de substâncias (geralmente de álcool), ou a exposição a episódios de vitimação na infância servem, muitas vezes, para enquadrar o crime $e$ atenuar a culpabilidade dos agressores (Angélico et al., 2014; Carlyle et al., 2008; Meyers, 1997; Pereyra, 2001; Richards et al., 2011; Taylor, 2008, 2009). Nos casos em que as vítimas de femicídio na intimidade padeciam de uma qualquer condição clínica, física ou psicológica, a exposição dos agressores ao stresse do cuidador (Gillespie et al., 2013; Taylor, 
2009) é, muitas vezes, indicada como estando na génese do crime.

As fontes às quais os/as jornalistas recorrem são também, muitas vezes, condicionadoras da construção das narrativas mediáticas sobre $\mathrm{o}$ femicídio na intimidade. Privilegia-se, grosso modo, a informação proveniente das forças policiais, das vizinhanças e de familiares próximos das vítimas e/ou dos agressores, não havendo o cuidado de reunir elementos que permitam uma avaliação integrada de cada caso, nomeadamente a análise de peritos/as na matéria (Carlyle et al., 2008; Wozniak e McCloskey, 2008). Os fatores sociais e as evidências científicas associadas ao crime são, por isso, obscurecidos, mantendo-se uma vez mais inexploradas as causas estruturais da violência de género (Meyers, 1997; Taylor, 2008).

Carlyle et al. (2008) sublinham que, além da comum culpabilização das vítimas pelos media, ao não serem apresentados todos os fatores envolvidos no femicídio, é falseada a perceção de necessidade de proteção das vítimas de violência na intimidade e são minimizados os fatores de risco a ter em consideração. Por conseguinte, o público poderá fazer uma leitura enviesada da realidade do femicídio, relativizando-a. De acordo com Taylor e Sorenson (2002), apenas os conteúdos noticiosos que dão enfoque social ao femicídio na intimidade contribuem para a sua compreensão, uma vez que a natureza do problema é social e não intra ou interpessoal.

$$
\text { Bullock e Cubert }
$$
identificaram quatro formas dos media enquadrarem o femicídio na intimidade na produção noticiosa, sendo que todas decorrem de uma perspetiva de dominância masculina e de normalização da violência de género. São enquadramentos ${ }^{1}$ do femicídio na intimidade os seguintes:

a) Conteúdo de fonte policial ou "apenas factos" - o/a jornalista privilegia a objetividade e prioriza como fontes de informação agentes de autoridade e decisores/as judiciais (e.g., polícias, juízes/as). A linguagem usada é predominantemente técnica, estando a descrição da relação entre a vítima e o ofensor, bem como do processo de

\footnotetext{
1 Por enquadramento entende-se aqui o processo jornalístico de seleção, interpretação e avaliação de determinados factos que serão predominantes na produção noticiosa, organizando a informação a veicular (Entman, 1993 apud Comas-d'Argemir, 2014).
} 
vitimação, praticamente ausente nas notícias;

b) Indicação/insinuação de que a vítima e o perpetrador são diferentes do/a cidadão/ã comum - o/a jornalista associa o femicídio à violência na intimidade, mas radica-o em determinados grupos sociais, destacando o abuso de substâncias e o cadastro criminal como elementos centrais na prática do crime;

c) Culpabilização da vítima e/ou desresponsabilização do perpetrador o/a jornalista discorre sobre a responsabilidade da vítima, habitualmente do sexo feminino, sugerindo o não cumprimento dos papéis de género a ela imputados, usando linguagem pejorativa ou pouco abonatória da conduta das mulheres. $\mathrm{O}$ perpetrador é apresentado como tendo algum tipo de défice (e.g., depressão, dependência de substâncias), o que dispersa a sua culpabilização;

d) $\mathrm{O}$ perpetrador excêntrico - o/a jornalista destaca a relação atípica entre a vítima e o agressor, indicando ambos como desviantes.

Estes enquadramentos não promovem, assim, uma leitura socialmente informada sobre a violência de género e, menos ainda, sobre o femicídio na intimidade. A proliferação de discursos distorcidos sobre os fenómenos criminais tem, pois, implicações do ponto de vista das representações e práticas sociais, aspeto que se discutirá seguidamente.

\section{O impacto das notícias sobre o femicídio na intimidade}

A forma como os/as protagonistas das notícias são associados/as a um determinado universo moral proporciona a criação/manutenção de julgamentos igualmente morais que poderão resvalar em atribuições erróneas de culpa e de responsabilidade (Chermak, 1995; Meyers, 1997). Na verdade, por ser fonte primária de informação sobre o crime (Wozniak e McCloskey, 2008), os meios de comunicação social têm a possibilidade de dizer às pessoas em e $o$ que pensar, podendo influenciar a opinião pública (Taylor e Sorenson, 2002) e, por conseguinte, as representações sociais sobre o objeto-notícia.

Neste sentido, Surette (1998) identifica cinco formas diferentes de influência dos meios de comunicação social na perceção coletiva da criminalidade e no medo do crime: a) 
substituição: pessoas que não têm fontes alternativas de conhecimento que substituam a informação mediática que promove o medo; b) ressonância: pessoas com experiência concreta de vitimação que corroborem ou possam ir ao encontro da informação veiculada pelos media; c) vulnerabilidade: pessoas menos capazes de prevenir a vitimação são mais facilmente influenciadas pelos conteúdos mediáticos; d) afinidade: pessoas que possuem semelhanças demográficas com as vítimas de crimes tornam-se igualmente mais receosas e mais suscetíveis de serem influenciadas pelos media; e e) máximo efeito: pessoas que sentem já elevados níveis de medo estão, por esse motivo, fora do alcance da influência dos media (Chiricos et al., 1997; Gomes, 2015: 89).

Olhando para o impacto das notícias de femicídio na intimidade junto da opinião pública, em geral, e das pessoas que estão envolvidas em processos de violência na intimidade, em particular, os estudos mostram que as notícias podem ter um efeito extremamente negativo (Vives-Cases et al., 2009). Os media podem não só acentuar as desigualdades de género, como contribuir inclusivamente para o aumento da criminalidade de género, nomeadamente do femicídio na intimidade.

$$
\text { Lagos e Toledo }
$$
apresentam como efeitos do impacto das narrativas mediáticas sobre $\mathrm{o}$ femicídio na intimidade os seguintes: a) representação da violência de género como um problema individual ou relacional - este efeito está diretamente relacionado com a propagação de uma visão socialmente descontextualizada do fenómeno, remetendo-o para a esfera da conflitualidade passional; b) efeito copycat ou mimetismo - este efeito dá conta do aumento de casos por imitação. São exemplos deste efeito os casos de mulheres que foram queimadas com ácido pelos seus maridos, em países como o Bangladesh, a Índia ou o Camboja, depois de terem sido mediatizadas situações análogas; c) aumento do medo junto das vítimas - as narrativas mediáticas sobre o femicídio agravam a perceção de vulnerabilidade das mulheres, podendo funcionar como um fator promotor de subordinação e desempoderamento; d) efeito protetor quando as notícias dão enfoque a iniciativas que promovem a prevenção e/ou a intervenção contra a violência de género, como medidas legislativas, 
políticas públicas ou condenações judiciais, parecem ter um efeito dissuasor para os agressores.

Pela sua potencial letalidade, a análise do efeito copycat ou mimetismo tem ganho, nas últimas décadas, especial relevo. O termo copycat crime difundiu-se na década de 1970, decorrente da ideia de que os media podem fornecer às sociedades modelos criminógenos (Surette, 2014). Partindo do pressuposto de que a exposição a notícias sobre crimes violentos pode engrossar o número desses mesmos crimes, o efeito de cópia traduz, como já referido, o risco da prática criminal por imitação (Jennings, 2005). Originalmente sinalizada nos estudos sobre o suicídio ("efeito Werther" - e.g., Phillips, 1974), esta tendência para a modelagem recentra a discussão sobre a responsabilidade dos media na produção noticiosa (Surette, 2014).

Um estudo pioneiro, realizado em Espanha, sobre o efeito das notícias veiculadas pela televisão sobre femicídio na intimidade (Vives-Cases et al., 2009) concluiu o aumento do crime em cerca de $32 \%$ a $42 \%$. Este deveu-se, entre outros fatores, à identificação dos/as espectadores/as com os casos noticiados, reforçando a sua motivação para o crime. Encontraram-se evidências de contágio nos sete dias após a difusão das notícias sobre femicídio, havendo uma diminuição dos crimes nos dias imediatamente a seguir à difusão de notícias/reportagens sobre prevenção/intervenção no âmbito de violência de género (efeito protetor). Também Lorente (2010), em Espanha, verificou que a exposição a notícias sobre criminalidade violenta pode encorajar os perpetradores e promover o medo entre as vítimas de violência na intimidade. Ter acesso ao modus operandi dos femicidas pode reforçar a decisão de imitá-los.

Perante tais evidências, que sugerem a existência de uma relação entre a exposição às notícias sobre $\mathrm{o}$ crime e as práticas criminais, acentua-se a responsabilidade dos media (informativos) no sentido do ajustamento das suas narrativas, por forma a prevenir a possibilidade de o efeito copycat se verificar. A título ilustrativo, refira-se o trabalho desenvolvido pela Organização Mundial de Saúde e as agências nacionais com vista a combater o efeito Werther, partindo do pressuposto de que se pode contrariar o potencial de imitação que decorre da exposição a notícias sobre o 
suicídio. Assim, foram criadas diretivas para a divulgação de casos de suicídio nos media, as quais contemplam uma sistematização das características que ora podem prevenir ora fazer despoletar o suicídio. O efeito protetor do impacto destas notícias ficou conhecido como o efeito Papageno (Niederkrotenthaler et al., 2010).

\section{Considerações finais}

Neste artigo, propusemo-nos refletir sobre o papel dos media como agentes de conhecimento, de socialização e de construção de realidades, bem como sobre os possíveis efeitos das narrativas mediáticas sobre os casos de violência contra as mulheres e, muito em concreto, sobre os casos de femicídio na intimidade nas representações sociais e práticas criminais. Foi nosso objetivo problematizar a relação entre o género e o crime nos media, salientando o caráter potencialmente lesivo dos discursos desgenderizados sobre o crime, sobretudo para as vítimas, uma vez que estes redundam frequentemente em visões social e culturalmente desenquadradas sobre o que motiva e alimenta a violência contra as mulheres na intimidade.

Reconhecendo o poder dos meios de comunicação social no sentido da influência e da formação da opinião pública (Morelli e Rey, 2011), discutimos, pois, a relação destes com a manutenção de estereótipos sobre as mulheres vítimas de violência, particularmente no contexto da intimidade. Concluímos que os media (informativos) parecem espelhar $\mathrm{e}$ reproduzir relações sociais de género, isto é, relações de poder desiguais (Buiten e Salo, 2007), fazendo proliferar representações de mulheres e homens, vítimas e agressores, arreigadas às premissas da diferenciação e hierarquização sexual. Parece claro, por isso, o risco do reforço da hegemonia masculina quando as narrativas mediáticas sobre o género, o crime e as relações sociais que a partir dos seus regimes se constituem são desprovidas de enquadramento social, cultural e político.

No que respeita ao femicídio na intimidade, os estudos apontam para a existência de uma associação entre a exposição às notícias e o comportamento das vítimas e dos agressores. Por outras palavras, a 
difusão de informação sobre este fenómeno está longe de ser inócua, parecendo refletir-se, em algumas circunstâncias, no aumento da prática do crime e, em outras, no incremento de denúncias e de procura de apoio por parte das vítimas.

Embora se tenha assistido nos últimos anos a um acréscimo de políticas e ações que visam definir estratégias de combate ao femicídio na intimidade (e.g., Declaração da Aliança Internacional das Mulheres, 2012, Declaração de Viena sobre o Femicídio, 2013, Femicide across Europe - COST Action 1206), o número de mulheres assassinadas pelos seus parceiros ou exparceiros continua a ser expressivo, o que significa que os intentos para pôr cobro a este flagelo não estão a surtir o efeito desejado, havendo ainda um longo caminho a percorrer. Parte deste caminho terá de ser feito, parece-nos, através dos media.

Se conscientes do seu papel educativo e preventivo, os media têm um potencial de mudança social e podem constituir-se como um instrumento de sensibilização, consciencialização, informação e pressão política (Castro et al., 2012). Nessa ótica, defendemos uma literacia crítica para os media, ou seja, uma abordagem crítica que interpele a cultura mainstream dos meios de comunicação social e que introduza na cena das narrativas mediáticas eixos de análise que são habitualmente invisibilizados, tais como o género, a raça, a sexualidade, a classe e o poder (Kellner e Share, 2007). Trata-se da promoção de um modelo alternativo de media, que seja necessariamente contrahegemónico, isto é, que resgate a voz de grupos frequentemente marginalizados, entre eles o das mulheres. Este modelo parte da premissa-base de que a audiência é ativa no processo de atribuição de significado às narrativas mediáticas e que, portanto, é preciso dar-lhe condições para pensar sobre o objeto-notícia.

Assim, a produção noticiosa sobre a violência contra as mulheres, em geral, e sobre o femicídio na intimidade, em particular, terá de enquadrar social e culturalmente o fenómeno (Sutherland, 2015), usando uma linguagem adequada, não promovendo a culpabilização das vítimas e a desculpabilização dos agressores, diversificando as fontes de informação e fornecendo às vítimas elementos que lhes permitam procurar apoio. 
Exemplos de boas práticas mediáticas estão disponíveis (e.g., Chacón, 2014) para serem replicados, não sendo inexistentes os referenciais que orientam as práticas e os discursos jornalísticos. Falta, contudo, uma ação coletiva e concertada que definitivamente institua uma cultura mediática assente no respeito pelos direitos humanos, através de um diálogo entre os órgãos de comunicação social, as entidades que os regulam, as associações profissionais, as universidades e o Estado.

\section{Referências bibliográficas}

Amâncio, Lígia (1993), “Género: Representações e identidades", Sociologia: Problemas e práticas, 14, 127-140.

Amâncio, Lígia (1994), Masculino e Feminino. A construção social da diferença. Porto: Afrontamento.

Angélico, Rocio; Dikenstein, Violeta; Fischberg, S.; Maffeo, Florencia (2014), "El feminicidio y la violencia de género en la prensa argentina: Un análisis de voces, relatos y actores", Universitas Humanística, 78, 281-303.

Azambuja, Mariana; Nogueira, Conceição (2007), "Violência de género: Uma reflexão sobre a variabilidade nas terminologias", Saúde em Debate, 31, 97-106.

Azambuja, Mariana; Nogueira, Conceição; Neves, Sofia; Oliveira, João (2013), "Gender Violence in Portugal: discourses, knowledges and practices", Indian Journal of Gender Studies, 20, 31-50.

Belknap, Joanne (2007), The invisible woman: gender, crime, and justice. Belmont: Thomson/Wadsworth.

Berger, Peter; Luckmann, Thomas (2004), A Construção Social da Realidade. Lisboa: Dinalivro [2a Ed.].

Berns, Nancy (2004), Framing the Victim: Domestic Violence, Media, and Social Problems. London: Aldine Transaction.

Buiten, Denise; Salo, Elaine (2007), "Silences stifling transformation: Misogyny and gender-based violence in the media", Agenda, 21(71), 115-121.

Bullock Cathy; Cubert, Jason (2002), "Coverage of Domestic Violence Fatalities by Newspapers in Washington State", Journal of Interpersonal Violence, 17(5), 475-499.

Campbell, Jacquelyn; Glass, Nancy, Nancy; Sharps, Phyllis; Laughon, Kathryn (2007), “Intimate partner homicide: Review and implications of 
research and policy", Trauma Violence Abuse, 8(3), 246-269.

Carlyle, Kellie; Scarduzio, Jennifer; Slater, Michael (2014), "Media Portrayals of Female Perpetrators of Intimate Partner Violence", Journal of Interpersonal Violence, 29 (13), 23942417.

Carlyle, Kellie; Slater, Michael; Chakroff, Jennifer (2008), "Newspaper coverage of intimate partner violence: skewing representations of risk", Journal of Communication, 58(1), 168186.

Carvalho, Margarida (2007), “A Construção da Imagem dos Imigrantes e das Minorias Étnicas pela Imprensa Portuguesa: Uma Análise Comparativa de Dois Jornais Diários" (Tese de Mestrado não publicada), Lisboa: ISCTE.

Campos, Carmen Hein (2015), "Feminicídio no Brasil: Uma análise crítico-feminista", Sistema Penal \& Violência, 7 (1), 103-115.

Caputi, Jane; Russell, Diana (1992), "Femicide: Sexist terrorism against women", in Diana Russell; Jill Radford (org.), Femicide: The politics of woman killing. New York: Twayne Publishers, 13-24.

Cerqueira, Carla (2008), "A Imprensa e a Perspectiva de Género. Quando elas são notícia no Dia Internacional da
Mulher", Observatorio (OBS*) Journal, $5,139-164$

Cerqueira, Carla (2012), "Quando elas (não) são notícia: mudanças, persistências e reconfigurações na cobertura jornalística sobre o Dia Internacional da Mulher em Portugal (1975-2007)" (Tese de Doutoramento não publicada), Braga: Universidade do Minho.

Chacón, María Cecilia (2014), "Coberturas que descubren Manual para periodistas que informan sobre violencia de género", Bolívia, Boris Miranda. Consultado a 08/02/2016, em http://www.contralosfemicidios.hn/ima ges/generales/descargas/publicaciones/2 015/Manual_los_periodistas_podemos _ayudar.pdf.

Chermak, Steven (1995), Victims in the news: Crime and the American news media. Boulder CO: Westview Press.

Chiricos, Ted; Eschholz, Sarah; Gertz, Marc (1997), "Crime, news and fear of crime: toward an identification of audience effects", Social Problems, 44, 342-57.

Comas-d'Argemir, Dolores (2014), "News of partner femicides: The shift from private issue to public problem", European Journal of Communication, 30(2) 121-136.

Connell, Raewyn (2002), Gender. Cambridge, Polity Press. 
Consalvo, Mia (1998), "3 shot dead in courthouse: Examining news coverage of domestic violence and mail-order brides", Women's Studies in Communication, 21(2), 188-211.

Conselho da Europa (2011), "Convenção de Conselho da Europa para a prevenção e o combate à violência contra as mulheres e a violência doméstica", Lisboa, CIG.

Dias, Isabel (2004), Violência na família. Uma abordagem sociológica. Porto: Afrontamento.

Dobash, Russell; Dobash, Emerson; Cavanagh, Kate; Lewis, Ruth (2004), "Not an Ordinary Killer, Just an Ordinary Guy: When Men Murder an Intimate Woman Partner", Violence Against Women, 10, 577-605.

Duarte, Vera; Cunha, Manuela Ivone (2014), "Violências e delinquências juvenis femininas: Aproximações à questão", in Vera Duarte; Manuela Ivone Cunha (eds.), Violências e Delinquências Juvenis Femininas: Género e (In)Visibilidades Sociais. Vila Nova de Famalicão: Húmus, 9-23. Consultado a 01/02/2014, em http://repositorium.sdum.uminho.pt/bits tream/1822/29620/1/IntroDelRaparigas. pdf.

Dutton, Donald; Nicholls, Tonia (2005), "The gender paradigm in domestic violence research and theory: Part 1-
The conflict of theory and data", Aggression and Violent Behavior, 11 (6), 680-714.

European Union Agency for Fundamental Rights (FRA) (2014), Violence against women: an EU-wide survey. Luxembourg: Publications Office of the European Union. Consultado a 08/02/2016, em http://fra.europa.eu/sites/default/files/fra -2014-vaw-survey-main-resultsapr14_en.pdf.

Gallagher, Margaret (2014), "Feminist scholarship and the debates on gender and communication", in Aimée Vega Montiel (ed.), Media and Gender: A Scholarly Agenda for the Global Alliance on Media and Gender. Paris: United Nations Educational, Scientific and Cultural Organization, 11-14. Consultado a 20/01/2016, http://www.unesco.org/new/fileadmin/ MULTIMEDIA/HQ/CI/CI/pdf/publicati ons/gamag_research_agenda_gallagher. pdf.

Gillespie, Lana; Richards, Tara; Givens, Eugena; Smith, Dwayne (2013), "Framing deadly domestic violence: why the media's spin matters in newspaper coverage of femicide", Violence Against women, 19 (22), 222245.

Gomes, Sílvia (2013), “A construção do pânico moral sobre os ciganos e os imigrantes na imprensa diária portuguesa", Revista Latitudes, 7 (2), 187-217. 
Gomes, Sílvia (2015), "Dos media e da construção das realidades criminais", in Manuela Ivone Cunha (ed.), Do Crime e do Castigo: Temas e Debates Contemporâneos. Lisboa: Editora Mundos Sociais, 81-98.

Hentig, Hans von (1948), The Criminal and His Victim: Studies in the Sociology of Crime. New Haven, CT: Yale University Press.

Jankey, Odireleng (2009), Passion Killings: A media and cultural perspective of intimate femicide in Botswana. Utah: College of Social Work, University of Utah.

Jennings, Lane (2005), "Combating Copycat Violence: Pop Culture's Exploitation of Criminal Acts Breeds More of Them", The Futurist, 39.

Jewkes, Yvonne (2011), Media and Crime. London: Sage. [2 $2^{\mathrm{a}}$ ed.].

Katz, Jack (1987), "What makes crime news?", Media, Culture \& Society, 9, 47-75.

Kellner, Douglas; Share, Jeff (2007), "Critical media literacy, democracy, and the reconstruction of education", in Donald Macedo; Shirley R. Steinberg (eds.), Media literacy: A reader. New York: Peter Lang Publishing, 3-23.

Lorente, Miguel (2010), "Violencia de género: Cuándo y cuánto", in Javier Fernández Arribas; Myriam Noblejas (eds.), Cómo informar sobre violencia contra la mujer en las relaciones de pareja. Valencia: Centro Reina Sofia, 16-20. Versão eletrónica consultada a 06/02/2016,

em https://igualdade.xunta.gal/sites/default/ files/files/documentos/como_informar_ violencia_parella.pdf.

Machado, Helena; Santos, Filipe (2008), "Crime, drama e entretenimento: o caso Maddie e a meta-justiça popular na imprensa portuguesa", Oficina do CES, 310, 132.

McCombs, Maxwell (2002). The agenda-setting role of the mass media in the shaping of public opinion. Apresentação na Conferência Mass Media Economics, London School of Economics. Versão eletrónica consultada a 10/02/2016, em http://sticerd.lse.ac.uk/dps/extra/McCo mbs.pdf.

Meyers, Anneke (2010), "To drunk to say no", Feminist Media Studies, 10 (1), 19-34.

Meyers, Marian (1997), News coverage of violence against women: Endangering blame. Thousand Oaks, CA: Sage.

Mendes, José Manuel (2004), "Media, públicos e cidadania: algumas notas breves", Revista Crítica de Ciências Sociais, 70, 147-158. 
Morelli, Mariana; Rey, Paula (2011), "La violencia hacia las mujeres en los médios de comunicación. Hallazgos del Observatorio de Medios 2010", in Los Derechos de las mujeres en la mira. Informe Anual de los Observatorios de Sentencias Judiciales y de Medios 2010. Buenos Aires: Equipo Latinoamericano de Justicia y Género, 19-43. Versão eletrónica consultada a 31/01/2016, em http://www.humanas.cl/?p=13868.

Neves, Sofia (2007), "As mulheres e os discursos genderizados sobre o amor: A caminho do "amor confluente" ou o retorno ao mito do "amor romântico"?", Revista Estudos Feministas, 15(3), 609627.

Neves, Sofia (2008), Amor, Poder e Violências na Intimidade: os caminhos entrecruzados do pessoal e do político. Coimbra: Quarteto.

Neves, Sofia; Nogueira, Conceição (2003), "A Psicologia feminista e a violência contra as mulheres na intimidade: A (Re)construção dos espaços terapêuticos", Psicologia \& Sociedade, 15, 46-64.

Neves, Sofia; Nogueira, Conceição (2010), "Deconstructing Gendered Discourses of Love, Power and Violence in Intimate Relationships", in Dana Jack; Alisha Ali (eds.), Silencing the Self Across Cultures Depression and Gender in the Social World. Oxford: Oxford University Press, 241-261.
Niederkrotenthaler, Thomas, Voracek, Martin, Herberth, Arno, Till, Benedikt, Strauss, Markus, Etzersdorfer, Elmar, Eisenwort, Brigitte \&, Sonneck, Gernot (2010), "Role of media reports in completed and prevented suicide: Werther $\mathrm{v}$. Papageno effects", The British Journal of Psychiatry, 197, 234-243.

Pasinato, Wânia (2011), "Femicídios e as mortes de mulheres no Brasil", Cadernos Pagu 37, 219-246.

Penedo, Cristina (2003), O crime nos media - O que nos dizem as notícias quando nos falam de crime. Lisboa: Livros Horizonte.

Pereyra, Marcelo (2011), "Pensar la violencia de género. Estrategias explicativas en los discursos periodísticos", in Los Derechos de las mujeres en la mira. Informe Anual de los Observatorios de Sentencias Judiciales y de Medios - 2010. Buenos Aires: Equipo Latinoamericano de Justicia y Género, 81-104. Versão eletrónica consultada a 31/01/2016, em http://www.humanas.cl/?p=13868.

Phillips, David (1974), “The Influence of Suggestion on Suicide: Substantive and Theoretical Implications of the Werther Effect", American Sociological Review_ 39 (3), 340-354.

Pina, Sara (2009), Media e Leis Penais. Coimbra: Edições Almedina. 
Pinto, Manuel; Pereira, Sara; Pereira, Luís; Ferreira, Tiago (2011), Educação para os Media em Portugal: experiências, actores e contextos. Lisboa: Entidade Reguladora para a Comunicação Social.

Porto, Mauro (2004), "Enquadramentos da mídia e política", in António Rubim (org.), Comunicação e Política: conceitos e abordagens. Salvador: EdUFBA, 73-104. Versão eletrónica consultada a 31/01/2016, em http://periodicos.ufpb.br/ojs2/index.php/ tematica/article/viewFile/21211/11708.

Richards, Tara; Gillespie; Lane Kirkland; Smith, Dwayne (2011), "Exploring News Coverage of Femicide: Does Reporting the News Add Insult to Injury?", Feminist Criminology, 6(3) 178-202.

Richards, Tara; Gillespie; Lane Kirkland; Givens, Eugena (2014), "Reporting Femicide-Suicide in the News: The Current Utilization of Suicide Reporting Guidelines and Recommendations for the Future", Journal of Family Violence, 29, (4), 453-463.

Russell, Diana, Radford, Jill (1992), Femicide: The politics of woman killing. New York: Twayne Publishers.

Russell, Diana; Harmes, Roberta (2001), Femicide in Global Perspective. New York: Teacher's College Press.
Russell, Diana (2008), "Femicide: Politicizing the Killing of Females. Strengthening Understanding of Femicide", in Strengthening Understanding of Femicide: Using Research to galvanize action and accountability, Conference: Washington. Versão eletrónica consultada a 20/01/2016, em http://www.path.org/publications/files/ GVR_femicide_rpt.pdf

Sacco, Vincent (1995), "Media constructions of crime", The Annals of the American Academy of Political and Social Science, 539: 141-154.

Simões, Rita (2008), A Violência Contra as Mulheres nos Media - Lutas de Género no Discurso das Notícias (1975-2002). Coimbra: Coimbra Editora.

Smith, Paige; Kathryn, Moracco; Butts, John (1998), "Partner Homicide in Context: A Population-Based Perspective", Homicide Studies, 2(4), 400-421.

Stöckl, Heidi; Devries, Karen; Rotstein, Alexandra; Abrahams, Naeemah; Campbell, Jacquelyn; Watts, Charlotte; Moreno, Claudia Garcia (2013), "The global prevalence of intimate partner homicide: a systematic review", The Lancet, 382(9895), 859 - 865. 
Surette, Ray (1998), Media, Crime and Criminal Justice. Belmont: West/ Wadsworth.

Surette, Ray (2014), "Estimating the Prevalence of Copycat Crime: A Research Note", Criminal Justice Policy Review, 25, 703-718.

Sutherland, Georgina, McCormack, Angus, Pirkis, Jane, Easteal, Patricia \&, Vaughan, Cathy (2015), "Media representations of violence against women and their children: State of knowledge paper", Australia's National Research Organisation for Women's Safety, November 2015. Versão eletrónica consultada a 23/01/2016, em http://media.aomx.com/anrows.org.au/s 3 fs-public/FINAL\%20Cobranded\%20Media\%20Representations _WEB.pdf.

Taylor, Catherine; Sorenson, Susan (2002), "The nature of newspaper coverage of homicide", Injury Prevention, 8,121-127.

Taylor, Rae; Jasinski, Jana (2008), "Femicide and the Feminist Perspective", Homicide Studies, 15(4), 341-362.

Taylor, Rae (2009), "Slain and Slandered: A Content Analysis of the Portrayal of Femicide in Crime News", Homicide Studies, 13(1), 21-49.

Toledo, Patsíli; Lagos, Claudia (2014), "The Media and Gender-Based Murders of Women: notes on the cases in Europe and Latin America", European Union Heinrich-Böll-Stiftung Organizartion. Versão eletrónica consultada a 10/02/2016, em http://eu.boell.org/sites/default/files/upl oads/2014/07/femicide_mc_ptoledo_cla gos_en.pdf.

United Nations Office on Drugs and Crime (UNODC) (2011), "Global Study on Homicide 2011. Trends, contexts, data", Vienna: United Nations Office on Drugs and Crime. Versão eletrónica consultada a 12/02/2016, em https://www.unodc.org/documents/dataand-

analysis/statistics/Homicide/Globa_stud y_on_homicide_2011_web.pdf.

Vives-Cases, Carmen Torrubiano, Jordi; Álvarez, Carlos (2009), "The effect of television news items on intimate partner violence murders", European Journal of Public Health, 19(6), 592596.

Wozniak, Jessica; McCosley, Kathy (2010), "Fact or fiction? Gender issues related to newspaper reports of intimate partner homicide", Violence Against Women, 16(8), 934-952.

WHO (2013). Global and regional estimates of violence against women: prevalence and health effects of intimate partner violence and nonpartner sexual violence. Geneva: WHO. Versão eletrónica consultada a 10/02/2016, em 
Periódico do Núcleo de Estudos e Pesquisas sobre Gênero e Direito

Centro de Ciências Jurídicas - Universidade Federal da Paraíba

V. 6 - No 01 - Ano 2017 - Mídia, Gênero \& Direitos Humanos

ISSN | 2179-7137 | http://periodicos.ufpb.br/ojs2/index.php/ged/index

http://apps.who.int/iris/bitstream/10665/

85239/1/9789241564625_eng.pdf. 